\title{
Sistemas de medição individualizada de água: como determinar as vazões de projeto para a especificação dos hidrômetros?
}

\section{Water submetering system: how to determine the flow rates for water meters specification?}

\begin{abstract}
Marina S. de Oliveira Ilha
Engenheira Civil. Mestre e Doutora em Engenharia Civil pela Escola Politécnica da Universidade de São Paulo (USP). Livre Docente da Faculdade de Engenharia Civil, Arquitetura e Urbanismo da Universidade Estadual de Campinas (Unicamp), onde ministra disciplinas e desenvolve pesquisas na área de sistemas prediais
\end{abstract}

\section{Lúcia Helena de Oliveira}

Engenheira Civil. Mestre e Doutora em Engenharia Civil pela Escola Politécnica da USP. Professora Doutora da USP, onde atua na área de Engenharia de Sistemas Prediais nos níveis de graduação de pós-graduação

Orestes M. Gonçalves

Engenheiro Civil. Mestre, Doutor e Livre Docente em Engenharia Civil pela Escola Politécnica da USP. Professor Titular da Escola Politécnica da USP, onde coordena 0 Grupo de Ensino e Pesquisa de Engenharia de Sistemas Prediais

\section{Resumo}

Este artigo tem como objetivo avaliar os resultados obtidos na estimativa das vazões de projeto para o dimensionamento de hidrômetros de sistemas prediais de água fria com medição individualizada, empregando um método probabilístico aberto e o método empírico recomendado na normalização brasileira. Como os resultados finais indicam grandes diferenças nas vazões de projeto estimadas pelos dois métodos, é importante realizar pesquisa de campo a fim de verificar os valores obtidos. O modelo probabilístico aberto permite que o projetista ajuste as variáveis relacionadas ao uso da água para refletir melhor a realidade das vazões no sistema predial em função de diferentes condições de utilização. Por isso, seu emprego apresenta-se mais vantajoso, principalmente em sistemas com medição individualizada, em que a especificação do hidrômetro é efetuada, entre outros parâmetros, em função da vazão de projeto.

Palavras-chave: sistemas prediais, medição individualizada de água, eficiência de uso da água, gestão do uso da água.

\begin{abstract}
The objective of this paper is to compare the results obtained in the estimate of the design flow rates to the dimension water meters of water submetering systems in buildings by means not only from an open probabilistic model but also from the empirical method recommended by the Brazilian Standard. As the final results show considerable differences in the design flow rates estimated by both methods, it is extremely important to perform field survey in order to check the obtained values. The open probabilistic model enables the practitioner to adjust the variables related to the water use to better reflect the flow rates in the plumbing system according to the different conditions of use. Due to this advantage, its use appears to be more beneficial than the empirical method, mainly concerning submetering systems where the specification of the water meters takes into account the design flow rate.
\end{abstract}

Keywords: plumbing systems, water submetering, efficient water use, water management.

\section{Introdução}

Há alguns anos os usuários de edifícios habitacionais vêm solicitando sistemas de medição individualizada de água, tal como ocorre com os sistemas prediais de energia e de gás. Um dos fatores que justificam essa reivindicação é o aumento da conscientização de que o sistema de medição individualizada permite o gerenciamento do consumo de água contribuindo para a redução de desperdícios desse insumo e, consequentemente, da cobrança da água efetivamente consumida nas atividades realizadas na unidade habitacional.

Denomina-se medição individualizada a setorização do consumo de água com a instalação de pelo menos um hidrômetro em cada 
unidade habitacional, de forma que seja possível medir o volume de água consumido.

Vários trabalhos foram desenvolvidos com o objetivo de avaliar o impacto de redução de consumo de água resultante do gerenciamento possibilitado pelo sistema de medição individualizada, com valores variando de 15 a 30\% (MALAN; CABTREE, 1997; ZEEB, 1998; YAMADA, 2001). No entanto, observa-se que para os apartamentos em que o consumo for inferior ao volume relativo à taxa mínima de tarifação, o sistema de medição individualizada terá somente função de propiciar o gerenciamento do consumo. Ressalta-se ainda que o volume referente à taxa mínima varia entre as concessionárias, e que as regras de tarifação poderão ser alteradas em função da obrigatoriedade da medição individualizada.

Os sistemas de medição individualizada de água são compostos por (Figura 1): coluna de distribuição (CD) - trecho que alimenta os hidrômetros quando este tem origem no reservatório superior; ramal de alimentação (RA) - trecho entre a coluna de distribuição e a montante do(s) hidrômetro(s); ramal de distribuição principal (RDP) - trecho a jusante do hidrômetro sem ramificação; ramal de distribuição secundário (RDS) - trecho que alimenta dois ou mais pontos de utilização e sub-ramal (SR) - trecho que alimenta um único ponto de utilização.

O dimensionamento de hidrômetros em sistemas com medição coletiva tem sido tarefa das concessionárias de água no Brasil. Disso decorre, em geral, um desconhecimento dos projetistas de sistemas hidráulicos prediais sobre os diferentes aspectos envolvidos nessa tarefa. Medidores inadequadamente dimensionados podem resultar na submedição do consumo, o que ocorre quando as vazões no ramal de alimentação são, em sua maioria, inferiores à vazão mínima dos hidrômetros e, portanto, não detectadas (PEREIRA, 2007).

Essa situação é bastante frequente em sistemas indiretos de abastecimento de edificações, em que o controle do abastecimento de água para o reservatório é efetuado por uma torneira de boia. As vazões ocorridas com o deslocamento do flutuador da torneira de boia são, em alguns momentos, extremamente baixas, não detectadas pelos medidores empregados.

No caso de um sistema de medição individualizada, o dimensionamento do hidrômetro depende da estimativa das vazões de projeto que irão ocorrer no ramal de alimentação das unidades autônomas, em que são abastecidos de forma direta os pontos de utilização de água. Vale destacar que, nesse caso, os ambientes sanitários com diferentes períodos de utilização, como banheiros, cozinha e área de serviço são abastecidos por uma mesma tubulação, sendo essa a principal diferença no estabelecimento das vazões, comparando-se com os sistemas com medição coletiva, em que é usual o emprego de colunas de distribuição abastecendo ambientes com padrões de uso similares.

Trabalhos anteriores desenvolvidos pelos autores deste artigo evidenciaram a necessidade de modelos mais adequados não só para o dimensionamento dos hidrômetros individuais, mas também para o dimensionamento do sistema de distribuição de água (OLIVEIRA, 2007; OLIVEIRA; ILHA; GONÇALVES, 2007a; OLIVEIRA; ILHA; GONÇALVES, 2007b).

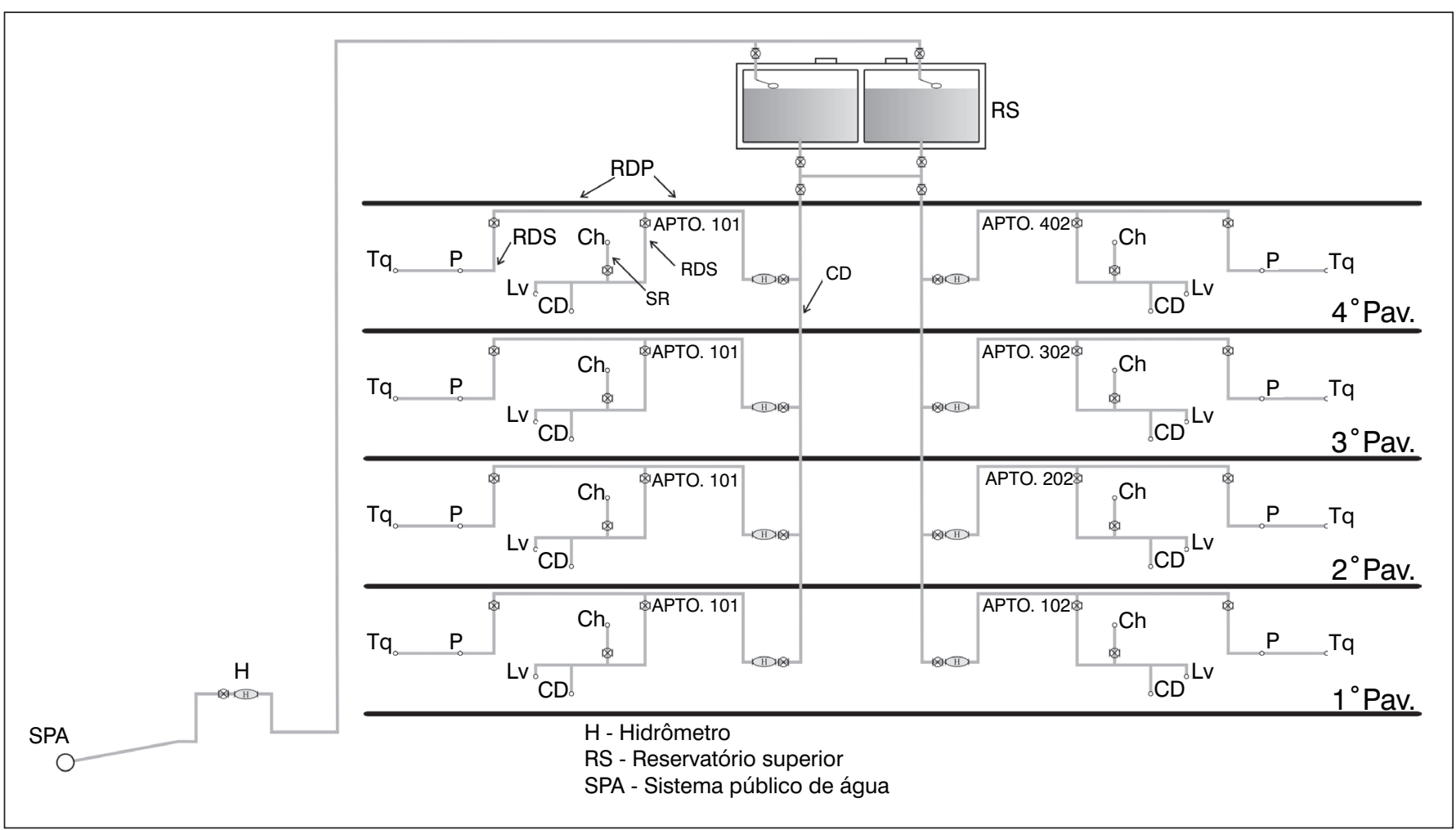

Figura 1 - Elementos do sistema de medição individualizada (Peres, 2006) 
Para que o sistema apresente a eficiência necessária, é imprescindível a seleção adequada dos medidores a serem utilizados, de modo a minimizar os erros na contabilização dos consumos efetivamente ocorridos. Assim, o correto estabelecimento das vazões de projeto é uma das premissas para o atendimento ao requisito de desempenho de 'confiabilidade' do sistema de medição individualizada.

Apesar de existirem, na década de 1980, métodos probabilísticos já desenvolvidos no Brasil, tais como o modelo proposto por Gonçalves (1986), a NBR 5.626 (ABNT, 1998) ainda recomenda o emprego de um método determinístico para o estabelecimento das vazões de projeto no sistema predial de água fria. Esse método, contudo, não é adequado, pois não considera que as vazões de projeto dependem das atividades dos usuários que, por sua vez, são função do tipo do edifício e das características do usuário; das características do edifício, definidas pela quantidade e pela distribuição da população e, ainda, das características, vazões e frequência de utilização dos aparelhos sanitários.

No sentido de evidenciar essas diferenças, este trabalho apresenta uma avaliação comparativa das vazões de projeto em três trechos, uma coluna e dois ramais de alimentação, obtidas pelo método probabilístico proposto por Gonçalves (1986) e pelo método empírico alemão da raiz quadrada, constante pela NBR 5.626 (ABNT, 1998).

\section{Métodos para a determinação de vazões de projeto em sistemas prediais hidráulicos}

Os modelos usualmente empregados para a determinação das vazões de projeto no sistema predial de água fria podem ser classificados em empíricos e probabilísticos.

Os modelos empíricos compreendem aqueles cuja técnica de determinação das vazões de projeto baseia-se na utilização de tabelas, gráficos e expressões matemáticas estabelecidas a partir da experiência e do julgamento de seus propositores.

Nos modelos de origem probabilística, incluem-se aqueles cuja técnica de determinação das vazões de projeto baseia-se no emprego de tabelas com valores de 'pesos', gráficos e expressões matemáticas estabelecidas a partir de conceitos probabilísticos, utilizando como ferramental básico a função de distribuição de probabilidades binomial.

\section{Métodos empíricos}

Basicamente existem dois tipos de expressão para os métodos empíricos. O primeiro deles é apresentado pela Equação 1:

$Q_{p}=f \cdot Q_{T}$ Equação 1

onde:

$\mathrm{Q}_{\mathrm{p}}$ é a vazão de projeto; $\mathrm{Q}_{\mathrm{T}}$ é a vazão total - somatório das vazões de todos os pontos de utilização; e f é o fator de simultaneidade de uso.
Esse fator de simultaneidade 'f' é obtido, dependendo do modelo, por meio de tabelas ou gráficos, ou de funções dependentes do número total de pontos de utilização.

O segundo tipo, denominado modelo da raiz quadrada, é apresentado pela Equação 2.

$\mathrm{Q}_{\mathrm{p}}=\mathrm{q}_{\mathrm{r}} \sqrt{\sum \mathrm{n}_{\mathrm{i}} \mathrm{P}_{\mathrm{i}}}$

Equação 2

onde:

$\mathrm{q}_{\mathrm{r}}$ é a vazão de referência; $\mathrm{P}_{\mathrm{i}}$ é o 'peso' atribuído ao aparelho sanitário do tipo i, função da sua vazão unitária $\left(q_{i}\right)$ com relação à vazão; $\mathrm{q}_{\mathrm{r}}$ e $\mathrm{n}_{\mathrm{i}}$ é o número de aparelhos sanitários do tipo i.

Essa equação é do modelo da raiz quadrada, de origem alemã, sendo ainda hoje utilizado com algumas particularidades. No Brasil, o método de pesos relativos, recomendado pela NBR 5.626 (ABNT, 1998) também tem origem no modelo da raiz quadrada, cuja expressão constante é apresentada pela Equação 3.

$\mathrm{Q}=0,3 \sqrt{\Sigma \mathrm{P}}$

Equação 3

onde:

Q é a vazão de projeto no trecho considerado, em L.s ${ }^{-1}$; $\sum$ P é o somatório dos pesos relativos de todas as peças de utilização, instaladas a jusante do trecho considerado.

\section{Métodos probabilísticos}

O modelo probabilístico clássico foi desenvolvido por Roy B. Hunter na década de 1930 e ainda é amplamente empregado em países como Estados Unidos e Inglaterra. O modelo binomial proposto considera que a probabilidade de que r ou mais aparelhos sanitários estejam em uso simultâneo em um grupo de $\mathrm{n}$ aparelhos instalados de um mesmo tipo $(n \geq r)$ é dada pela Equação 4 .

$P(x \geq r)=\sum_{x=r}^{n}\left(\begin{array}{l}n \\ x\end{array}\right) p^{x}(1-p)^{n-x}$

Equação 4

onde:

p é a probabilidade de funcionamento de um aparelho sanitário.

Considerando um fator de falha $\varepsilon$ igual a 0,01 , ou seja, $\mathrm{P}(\mathrm{x}$ $\geq \mathrm{r})<\varepsilon$, Hunter construiu curvas baseadas nas probabilidades de cada tipo de aparelho $\left(\mathrm{p}_{\mathrm{i}}\right)$, determinando o número de aparelhos $\left(r_{i}\right)$ em uso simultâneo e as respectivas vazões de projeto. A partir dessas curvas desenvolveu o conceito de 'unidades de contribuição', funcionando como 'pesos' associados a cada tipo de aparelho sanitário e, assim, simplificando a obtenção das vazões de projeto $\left(Q_{p}\right)$.

A partir do modelo de Hunter foram desenvolvidos outros modelos similares. Modelos mais evoluídos foram os propostos por 
Webster (1972), usando a distribuição binomial generalizada; e por Courtney (1976), usando a distribuição multinomial.

Com o objetivo de verificar os resultados obtidos com o emprego de alguns modelos determinísticos e probabilísticos, Gonçalves (1986) apresenta uma simulação efetuada com vários deles, sendo obtida uma grande variabilidade de valores para a vazão de projeto em um mesmo trecho do sistema: entre 1,2 L.s e $^{-1}$ 30,2 L.s ${ }^{-1}$.

Gonçalves (1986) cita que a maioria dos modelos estudados consta de procedimentos simplistas, fundamentados em considerações teóricas ou não, que nem sempre representam a complexidade do problema. A tendência dos propositores dos métodos por ele estudados é de formular modelos fechados de caráter universal, nem sempre adequados às particularidades de cada situação de projeto, não fornecendo aos engenheiros condições necessárias à tomada de decisão. A partir dessa avaliação, o referido autor propôs um modelo aberto para a determinação das demandas de água em sistemas prediais, a qual pudesse representar as condições reais de cada situação de projeto. Entende-se por modelo aberto aquele em que o projetista possa definir os parâmetros estatísticos de entrada para cada circunstância de projeto e estabelecer os fatores de falha admissíveis para o sistema predial de distribuição de água.

Segundo Gonçalves (1986), a ocorrência de vazões em um sistema predial de distribuição de água depende da interação entre o usuário e o sistema de equipamentos sanitários, nos pontos de utilização, conforme os seguintes fatores: atividades dos usuários, função do tipo de edifício - habitação, escola, hotel etc. -, e das características dos usuários, determinadas por aspectos fisiológicos, regionais, culturais, sociais e climáticos; características do edifício, função da população - quantidade e distribuição - e da organização espacial; características do conjunto de aparelhos sanitários, função dos tipos de aparelho e do número de aparelhos sanitários.

As variáveis intervenientes, as quais consideram os fatores acima, influenciando as vazões nos sistemas, são assim agrupadas no modelo: frequência de utilização do conjunto de aparelhos sanitários e vazões unitárias de cada tipo de aparelho sanitário (q).

A frequência de utilização do conjunto de aparelhos sanitários é representada no modelo pelas seguintes variáveis: duração da descarga de um aparelho sanitário, denotada por $\mathrm{t}$ - período compreendido entre o início da descarga (abertura de um componente de utilização como, por exemplo, uma torneira) e o final da descarga (fechamento do componente de utilização, caracterizado pela vazão nula); cabe comentar que reduzir os valores dessa variável, para determinados tipos de aparelhos, é um dos objetivos dos programas de conservação de água; intervalo de tempo entre descargas consecutivas de um aparelho sanitário, denotado por $\mathrm{T}$, que depende do número de usos por pessoa durante o período de pico, da população atendida e do número de aparelhos sanitários disponíveis no ambiente sanitário, tendo sido proposto um modelo de teoria das filas para a determinação dessa variável, e número de aparelhos sanitários instalados à jusante do trecho da tubulação, denotado por $\mathrm{n}$.

As variáveis aleatórias t e T são representadas pela função densidade de probabilidade do tipo Erlang ou exponencial, e q é representada pela função densidade de probabilidade do tipo Gama.

No modelo, as variáveis t e q representadas pelas estatísticas de média e variância, se constituem em dados de entrada. A média e a variância da duração da descarga podem ser determinadas por meio de levantamentos em campo, conforme o conduzido por Ilha (1992) ou então pelo método de estimação por três pontos característicos (GAARSLEV, 1969 apud GONÇALVES, 1986): um valor mínimo $\left(\mathrm{t}_{\text {min }}\right)$, outro mais provável $\left(\mathrm{t}_{\text {prov }}\right)$ e outro máximo $\left(\mathrm{t}_{\text {maxx }}\right)$, empregando as Equações 5 e 6 para a determinação da média $\left(\mu_{t}\right)$ e da variância $\left(\sigma_{\mathrm{t}}^{2}\right)$, respectivamente.

$$
\begin{aligned}
& \mu_{\mathrm{t}}=\frac{\mathrm{t}_{\text {min }}+3 * \mathrm{t}_{\text {prov }}+\mathrm{t}_{\text {max }}}{5} \\
& \sigma^{2}{ }_{\mathrm{t}}=\frac{\left(\mathrm{t}_{\text {max }}-\mathrm{t}_{\text {min }}\right)^{2}}{25}
\end{aligned}
$$

De maneira análoga, a vazão unitária de cada aparelho (q) e o número de usos de um determinado aparelho (u) podem também ser determinados por meio de levantamentos em campo com o cálculo da média e da variância ou a partir do método da estimação por três pontos, utilizando expressões similares às anteriores.

Por fim, o intervalo entre dois usos consecutivos ( $\mathrm{T}$ ) depende de diversos fatores, que podem ser representados pelas seguintes variáveis:

- número de aparelhos do tipo considerado instalados no ambiente sanitário (n);

- número de usos per capita de um tipo de aparelho durante o período de pico (u);

- população atendida pelo ambiente sanitário no qual o aparelho está instalado (P).

Vale ressaltar que um 'tipo' de aparelho é caracterizado por um conjunto de parâmetros no período de maior utilização, denominado período de pico: número de usos per capita, duração da descarga, intervalo entre duas descargas consecutivas e vazão unitária. Assim, o lavatório da suíte, que atende a duas pessoas, é um 'tipo' diferente de aparelho quando comparado ao lavatório do banheiro social, que atende, por exemplo, a outras quatro pessoas, considerando que esse banheiro atenda a dois dormitórios com duas pessoas cada.

O número de usos per capita de cada tipo de aparelho sanitário no período de pico $(u)$ pode ser determinado de maneira similar ao da vazão unitária e da duração da descarga, ou seja, a partir de levantamentos em campo, com o cálculo da média e da variância ou a partir do método da estimação por três pontos, utilizando-se de expressões análogas às apresentadas anteriormente. 
A população atendida pelo aparelho sanitário corresponde ao número de pessoas que utilizam o aparelho em questão (P). No caso de edificações comerciais, a população pode ser estimada a partir da densidade populacional (número de pessoas por $\mathrm{m}^{2}$ ) e da área de influência do ambiente sanitário (área dos ambientes onde estão as pessoas que utilizam o ambiente sanitário em que se encontra o aparelho sanitário em estudo).

Dessa forma, a média e a variância do intervalo entre dois usos consecutivos de um aparelho sanitário no período de pico podem ser determinadas a partir das Equações 7 e 8 .

$\mu_{\mathrm{T}}=\frac{\mathrm{n} \cdot \mathrm{t}_{\mathrm{p}}}{\mathrm{P}}\left(\frac{1}{\mu_{\mathrm{u}}}+\frac{\sigma_{\mathrm{u}}^{2}}{\mu_{\mathrm{u}}^{3}}\right)$

Equação 7

$\sigma_{\mathrm{T}}^{2}=\left(\frac{\mathrm{n} \cdot \mathrm{t}_{\mathrm{p}}}{\mathrm{P}}\right)^{2} \frac{\sigma_{\mathrm{u}}^{2}}{\mu_{\mathrm{u}}^{4}}$

Equação 8

Assim, a vazão no sistema pode ser determinada pela Equação 9.

$\mathrm{Q}=\sum_{i} \mathrm{r}_{\mathrm{i}} \mathrm{q}_{\mathrm{i}}$

Equação 9

onde:

$r_{i}$ é o número de aparelhos do tipo i, em uso simultâneo, o qual segue uma distribuição beta-binomial, apresentada na Equação 10, com parâmetros $a_{i}, b_{i}$, e dependentes de $p_{i}$, dado pela Equação 11:

$r_{i}^{d}=B-B\left(a_{i}, b_{i}, n_{i}\right)$

Equação 10

$p_{i}=t_{i} / T_{i}$

Equação 11

sendo $\mathrm{q}_{\mathrm{i}}$ a vazão unitária do aparelho do tipo i.

Com os valores da média e desvio padrão de $Q\left(\mu_{Q}, \sigma_{Q}\right)$ é possível determinar os valores da média e desvio padrão da variável Q' $\left(\mu_{Q}, \sigma_{Q}\right)$ que representa os valores não nulos $(Q / Q \neq 0)$ da vazão, no período de pico. A função densidade de probabilidades que representa a variável Q' $(\mathrm{Q} / \mathrm{Q} \neq 0$ ) é do tipo Gama, conforme apresentada na Equação 12 e Figura 2.

$f\left(Q^{\prime}\right)=\frac{\lambda_{Q}^{r_{Q}}}{\Gamma_{\left(r_{Q}\right)}} \cdot Q^{\mathrm{r}_{\mathrm{Q}^{-1}}} \cdot \mathrm{e}^{\mathrm{Q}^{\prime}}$

Equação 12

sendo

$\lambda_{Q}>0, r_{Q}>0$

O fator de falha local máximo $\left(\varepsilon_{\text {LMÁX }}\right)$ representa a probabilidade de que a vazão de projeto seja ultrapassada, considerando-se apenas os intervalos de tempo em que ocorrem vazões no trecho considerado durante o período de pico. Assim, se o desejado é que a vazão de projeto calculada para o trecho não seja ultrapassada em mais do que $5 \%$ do tempo em que ocorrem vazões no período de pico, o fator de falha local deverá ser $5 / 100=0,05$.

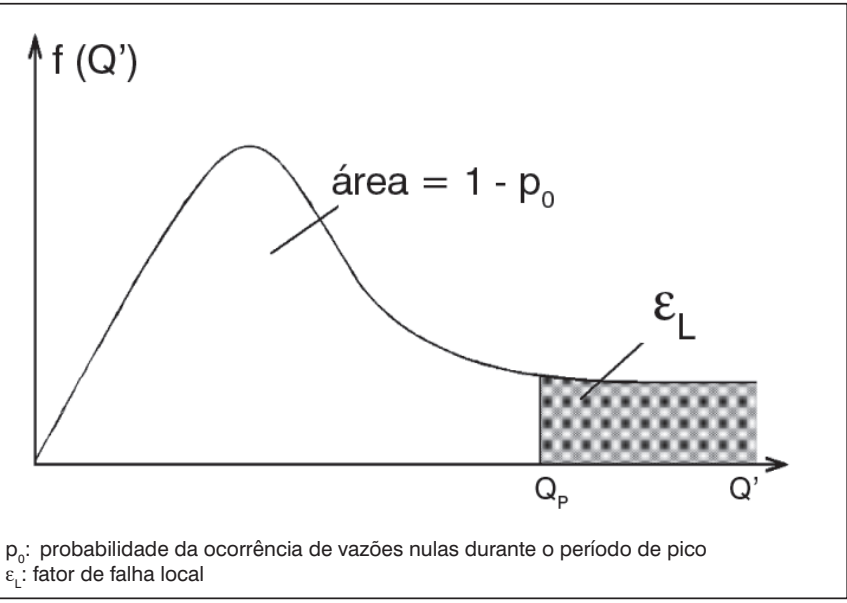

Figura 2 - Função densidade de probabilidades do tipo Gama

O modelo considera também um fator de falha global $\left(\varepsilon_{\mathrm{G}}\right)$, ou seja, a probabilidade de que a vazão de projeto (nula e não-nula) seja ultrapassada durante o período de pico considerado. Esse fator exprime a falha admitida no sistema. Assim, se o desejado é que a vazão de projeto calculada para o trecho não seja ultrapassada em mais do que $1 \%$ do tempo, o fator de falha global deverá ser $1 / 100$ $=0,01$.

Considerando o fator de falha local e a aproximação de Johnston para a função Gama, é possível calcular o valor z e, consequentemente, a vazão de projeto $\mathrm{Q}_{\mathrm{p}}$ pode ser determinada usando a Equação 13:

$\mathrm{Q}_{\mathrm{p}}=\mu_{\mathrm{Q}^{\prime}}+\mathrm{z} \sigma_{\mathrm{Q}^{\prime}}$

Equação 13

Conforme mencionado, foi desenvolvido um modelo de Teoria de Filas (tipo M/M/C), que por intermédio de critérios de desempenho, permite determinar o número necessário de aparelhos sanitários que devem ser instalados, em banheiros, e os valores da média de desvio padrão da variável aleatória $\mathrm{T}$ do modelo de demanda, conforme apresentado em Gonçalves (1986). Esse modelo de Teoria das Filas foi utilizado como referência pelo professor Thomas P. Konen do Stevens Institute of Technology (Estados Unidos) para a definição do modelo de determinação de aparelhos sanitários em banheiros de escritórios, elaborado para a American Society of Plumbing Engineers (ASPE).

O caráter aberto do modelo de demanda, no qual todas as variáveis de entrada podem ser específicas para diferentes situações de projeto, foi explorado em três aplicações apresentadas em Gonçalves (1989). Neste trabalho, foram avaliadas as variações das demandas de água em um edifício residencial em função da variação do número de pessoas atendidas por um mesmo banheiro, da variação das condições regionais e climáticas e da variação dos períodos analisados ao longo do dia. 


\section{Escolha do método para a determinação da vazão de projeto em sistema de medição individualizada}

Observa-se que o método empírico, anteriormente apresentado, não considera as variáveis apresentadas nos métodos probabilísticos e trata da mesma forma edifícios com características diferentes como, por exemplo, um edifício residencial com apartamentos de um banheiro e população de duas pessoas e outro com um banheiro e cinco pessoas. Sabe-se, contudo, que essas duas situações resultam em vazões de projeto completamente diferentes.

O regime de uso dos aparelhos considerado pelo método recomendado pela NBR 5.626 (ABNT, 1998), em geral, não ocorre em edifícios residenciais com medição individualizada, uma vez que considera o mesmo período de pico para a utilização de todos os aparelhos sanitários do apartamento. Esse regime é verificado em sistemas convencionais, com uma coluna para cada ambiente sanitário, onde a maior frequência de utilização dos aparelhos ocorre praticamente em um mesmo período como, por exemplo, o uso de chuveiros e de bacias sanitárias no início da manhã.

No caso dos sistemas de medição individualizada, os trechos da tubulação de água, onde estão instalados os medidores, atendem diferentes tipos de ambientes sanitários, tais como: cozinhas, banheiros e áreas de serviço. Ressalta-se que os picos de consumo de água nesses ambientes não coincidem, pois o horário de funcionamento de pico da área de serviço não é o mesmo do banheiro social e, assim, para os outros ambientes.

Dessa forma, em uma cidade como São Paulo, um trecho da tubulação de água fria, com hidrômetro instalado, pode atender simultaneamente banheiros, com períodos de pico das 6 às 8 horas e das 18 às 20 horas, e cozinha, com período de pico das 11 às 14 horas e, em outros casos, das 18 às 20 horas. Na condição mais desfavorável, ou seja, naquela em que um maior número de pontos de consumo é utilizado ao mesmo tempo, o período de pico ocorrerá das 18 às 20 horas com o uso simultâneo de alguns aparelhos sanitários do banheiro e da cozinha.

Ressalta-se ainda que, tanto para sistemas convencionais quanto para sistemas com medição individualizada, a utilização de válvula de descarga, conforme a NBR 5.626 (ABNT, 1998), requer coluna exclusiva. No caso de sistemas de medição individualizada, a principal razão em não se utilizar válvula de descarga é que, em função da grande diferença de vazão da válvula de descarga, em relação aos outros aparelhos sanitários, o medidor dimensionado para a vazão da válvula de descarga ficaria superdimensionado para as vazões dos outros aparelhos, o que resultaria na submedição.

\section{Metodologia}

A avaliação comparativa dos valores de vazão de projeto, obtidos pelos métodos de pesos relativos, recomendado pela NBR 5.626
(ABNT, 1998) e pelo método probabilístico aberto (Gonçalves, 1986), foi desenvolvida por meio das atividades descritas na sequência: definição de tipologias de edifícios residenciais a serem estudadas; definição dos parâmetros de entrada para as simulações e realização das simulações e análises.

Foram consideradas tipologias usualmente empregadas em edifícios residenciais, quais sejam: um dormitório e um banheiro (1D/1B) para uma população de duas pessoas; dois dormitórios e um banheiro (2D/1B) para uma população de cinco pessoas; dois dormitórios e dois banheiros (2D/2B) para uma população de cinco pessoas. Cada apartamento considerado possuía uma cozinha e uma área de serviço.

Em cada apartamento, foram considerados os seguintes aparelhos sanitários:

- banheiro (social ou suíte): uma bacia sanitária com volume nominal de descarga de 6 litros (BS), um lavatório (Lv) e um chuveiro elétrico $(\mathrm{Ch})$;

- $\quad$ cozinha: uma pia (P);

- área de serviço: uma máquina de lavar roupa (MLR) e um tanque $(\mathrm{Tq})$.

Conforme apresentado, no caso das simulações com o método de pesos relativos, os dados de entrada referem-se aos pesos dos aparelhos sanitários, sendo considerados os valores constantes na NBR 5.626 (ABNT, 1998), os quais são reproduzidos na Tabela 1.

Para o método probabilístico aberto proposto por Gonçalves (1986), além das vazões unitárias dos aparelhos, devem ser estimados: a duração média da descarga e o número médio de usos, por pessoa, de cada tipo de aparelho no período de pico; a duração do período de pico; o número de pessoas atendidas pelos ambientes sanitários onde se encontram os aparelhos a serem abastecidos em cada trecho do sistema e os fatores de falha local e global.

Para a estimativa da vazão média de cada tipo de aparelho, foi adotado o método da estimação por três pontos. A duração média da descarga e o número médio de usos por pessoa de cada aparelho no período de pico foram determinados a partir da experiência dos autores deste artigo e também do trabalho desenvolvido por Ilha (1991). As Tabelas 2 e 3 apresentam os valores considerados para esses parâmetros.

Foram considerados os mesmos valores da vazão unitária média e da duração média da descarga de cada aparelho para o banheiro social e para a suíte. Conforme citado anteriormente, foi considerado chuveiro elétrico em ambos os banheiros (aquecimento individual, no próprio ponto de consumo), o qual, para garantir um aquecimento aceitável, opera uma vazão bem mais baixa do que a utilizada em sistemas centralizados de água quente. 
A definição da duração do período de pico também foi efetuada em função dos resultados obtidos por Ilha (1991), sendo considerados três valores desse parâmetro, para possibilitar uma análise comparativa dos resultados obtidos: 1 hora, 1 hora e 30 minutos e 2 horas.

Os seguintes valores foram considerados para a população atendida em cada ambiente sanitário, conforme o caso simulado:

- $\quad$ simulação A: banheiro da suíte: duas pessoas; cozinha: uma pessoa e área de serviço: uma pessoa;

- $\quad$ simulação B: banheiro social: cinco pessoas; cozinha: um pessoa e área de serviço: uma pessoa;

- simulação C: banheiro social: três pessoas; banheiro da suíte: duas pessoas; cozinha: uma pessoa e área de serviço: uma pessoa.

As configurações das simulações estudadas estão apresentadas na Figura 3.

Por fim, considerou-se que a vazão de projeto calculada para cada trecho em estudo não deveria ser ultrapassada em mais do que $1 \%$ do tempo, o que resulta na definição de um fator de falha global de 0,01. Para o fator de falha local, considerou-se o valor proposto por Gonçalves (1986), ou seja, 0,05.

Tabela 1 - Pesos dos aparelhos utilizados na simulação do do método da NBR 5.626 (ABNT, 1998)

\begin{tabular}{ll} 
Aparelho & Peso \\
\hline Lavatório & 0,3 \\
Bacia sanitária & 0,3 \\
Chuveiro elétrico & 0,1 \\
Pia & 0,7 \\
Máquina de lavar roupa & 1 \\
Tanque & 0,7
\end{tabular}

\section{Realização das simulações e análises}

A determinação das vazões de projeto foi efetuada com o método probabilístico, cujo detalhamento pode ser encontrado em Gonçalves

Tabela 2 - Valores de duração de descargas (por usuário e por uso) e de vazão dos aparelhos sanitários utilizados na simulação do modelo probabilístico aberto

\begin{tabular}{lrrrccc} 
Aparelho & \multicolumn{3}{c}{ Duração da descarga (s) } & \multicolumn{3}{c}{ Vazão $\left(\right.$ L.s $\left.{ }^{-1}\right)$} \\
\cline { 2 - 7 } sanitário & Mín & Mais prov & Máx & Mín & Mais prov & Máx \\
\hline Lv & 15 & 25 & 30 & 0,05 & 0,07 & 0,10 \\
BS & 45 & 68 & 85 & 0,08 & 0,10 & 0,15 \\
Ch & 300 & 480 & 900 & 0,05 & 0,09 & 0,12 \\
P & 15 & 30 & 60 & 0,10 & 0,12 & 0,20 \\
\hline MLR & 480 & 720 & 960 & 0,10 & 0,13 & 0,19 \\
Tq & 20 & 30 & 40 & 0,10 & 0,15 & 0,20 \\
\hline
\end{tabular}

Mín: mínimo; Mais prov.: mais provável; Máx: máximo.

Tabela 3 - Valores do número de usos per capita utilizados na simulação do modelo probabilístico aberto

\begin{tabular}{|c|c|c|c|c|c|c|c|c|c|}
\hline \multirow{2}{*}{$\begin{array}{l}\text { Aparelho } \\
\text { sanitário }\end{array}$} & \multicolumn{3}{|c|}{$\begin{array}{c}\text { Simulação A } \\
\text { Número de usos } \\
\text { per capita }\end{array}$} & \multicolumn{3}{|c|}{$\begin{array}{l}\text { Simulação B } \\
\text { Número de usos } \\
\text { per capita }\end{array}$} & \multicolumn{3}{|c|}{$\begin{array}{c}\text { Simulação C } \\
\text { Número de usos } \\
\text { per capita }\end{array}$} \\
\hline & Mín & $\begin{array}{l}\text { Mais } \\
\text { prov }\end{array}$ & Máx & Mín & $\begin{array}{l}\text { Mais } \\
\text { prov }\end{array}$ & Máx & Mín & $\begin{array}{l}\text { Mais } \\
\text { prov }\end{array}$ & Máx \\
\hline Lv social & 1 & 1 & 2 & 0 & 1 & 2 & 1 & 1 & 2 \\
\hline Lv suíte & -- & -- & -- & -- & -- & -- & 0 & 1 & 1 \\
\hline BS social & 0 & 1 & 1 & 0 & 1 & 1 & 0 & 1 & 1 \\
\hline BS suíte & --- & --- & --- & --- & -- & --- & 0 & 1 & 1 \\
\hline Ch social & 0 & 1 & 1 & 0 & 1 & 1 & 0 & 1 & 1 \\
\hline Ch suíte & --- & --- & --- & --- & --- & --- & 0 & 1 & 1 \\
\hline$P$ & 3 & 4 & 6 & 3 & 5 & 8 & 3 & 4 & 6 \\
\hline MLR & 0 & 1 & 2 & 0 & 1 & 2 & 0 & 1 & 2 \\
\hline $\mathrm{Tq}$ & 0 & 1 & 1 & 0 & 1 & 1 & 0 & 1 & 1 \\
\hline
\end{tabular}

Mín: mínimo; Mais prov: mais provável; Máx: máximo.

Lv: lavatório; BS: bacia sanitária; Ch: chuveiro; P: pia de cozinha; MLR: máquina de lavar roupas; Tq: tanque de lavar roupas.

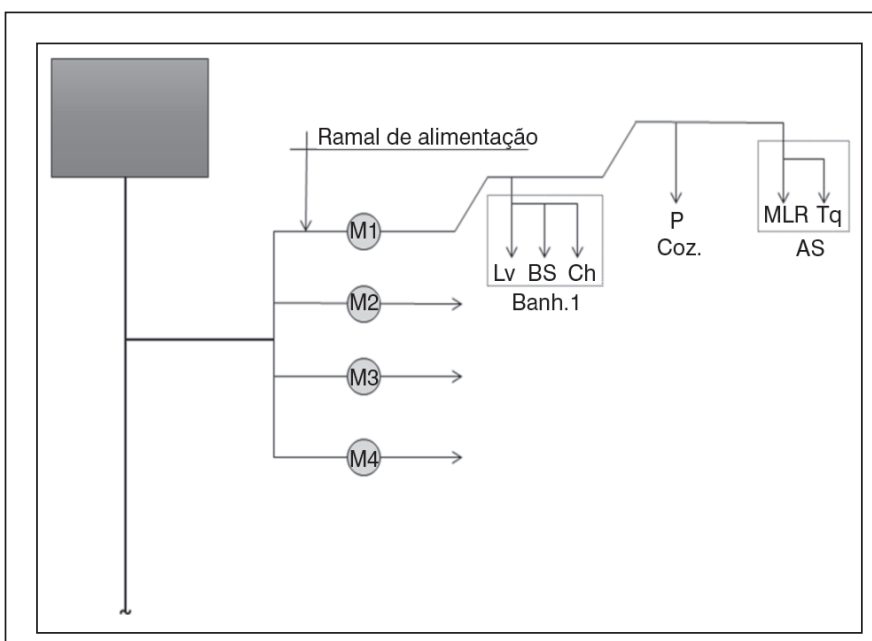

A

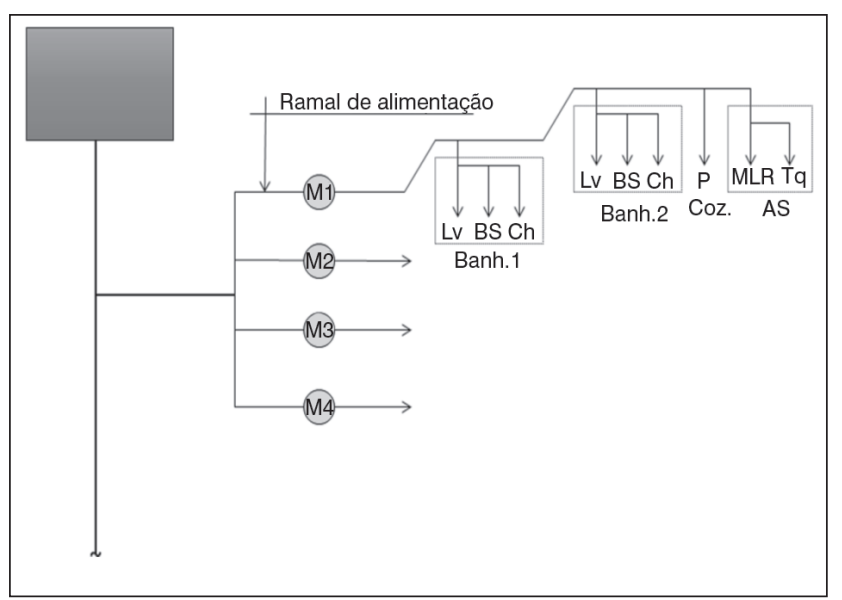

B

Lv: lavatório; BS: bacia sanitária; Ch: chuveiro elétrico; P: pia de cozinha; MLR: máquina de lavar roupas; Tq: tanque de lavar roupas; Banh.: banheiro; Coz.: cozinha; AS: área de serviços; M: hidrômetro.

Figura 3 - (a) Configurações de sistemas com um banheiro; e (b) com dois banheiros 
(1986). Para tanto, foi empregado um programa computacional, denominado ProAcqua, o qual constitui parte do material didático disponibilizado nos cursos de capacitação de profissionais para o projeto, a execução, o uso e a operação de sistemas com medição individualizada, o qual vem sendo oferecido dentro de um convênio entre o Centro de Desenvolvimento e Documentação da Habitação e Infraestrutura Urbana e a Companhia de Saneamento Básico do Estado de São Paulo - Sabesp (CEDIPLAC, 2010).

As situações de projeto simuladas são apresentadas na Tabela 4.

A partir dos resultados obtidos nas simulações, foram determinados os acréscimos (ou decréscimos) das vazões de projeto obtidas com o método probabilístico comparativamente aos valores obtidos com o método de pesos relativos previsto na NBR 5.626 (ABNT,1998).

\begin{tabular}{|c|c|c|c|c|}
\hline \multirow[b]{2}{*}{ 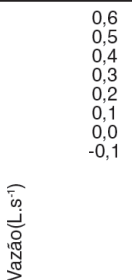 } & & & & \\
\hline & $\begin{array}{c}\text { Probabilístico } \\
\text { (2h) }\end{array}$ & $\begin{array}{l}\text { Probabilístico } \\
\text { (1h30min) }\end{array}$ & $\begin{array}{c}\text { Probabilístico } \\
\text { (1h) }\end{array}$ & NBR 5626 \\
\hline - Sim. A & 0,21 & 0,23 & 0,26 & 0,53 \\
\hline Sim. B & 0,23 & 0,26 & 0,33 & 0,53 \\
\hline$\square$ Sim. C & 0,24 & 0,28 & 0,34 & 0,58 \\
\hline
\end{tabular}

Figura 4 - Vazões de projeto no ramal de alimentação obtidas pelo método probabilístico aberto e pela NBR 5.626 (ABNT, 1998)

\section{Resultados e discussão}

Os resultados obtidos pelo método probabilístico indicam valores de vazão inversamente proporcionais aos valores de período de pico, conforme apresentado na Figura 4. Esse comportamento não ocorre com o método recomendado pela NBR 5.626 (ABNT,1998), cujo resultado da aplicação não depende do período de pico.

Nos ramais de alimentação, a aplicação do método probabilístico aberto resultou em valores de vazão que variam de 0,21 a 0,34 L.s s $^{-1}$, ou seja, um aumento de $62 \%$ quando o período de pico reduz de 2 para 1 hora, enquanto o valor obtido pela NBR 5.626 (ABNT,1998) foi de 0,53 L.s. ${ }^{-1}$ para as simulações A e B e de 0,58 L.s ${ }^{-1}$ para a simulação C.

Esses resultados demonstram que o método recomendado pela norma brasileira pode resultar em superestimativa das vazões de projeto nos ramais de alimentação de sistemas de medição individualizada. Ressalta-se ainda que o valor de vazão que será utilizado no dimensionamento do hidrômetro na simulação C, para a situação mais crítica considerada no método probabilístico, que é para período de pico de 1 hora, atinge no método da NBR 5.626 (ABNT,1998) um valor de 0,58 L.s.-1, ou seja, cerca de $70 \%$ acima do máximo valor obtido pelo método probabilístico, $0,34 \mathrm{~L} \cdot \mathrm{s}^{-1}$.

Considerando-se que os parâmetros fundamentais para a seleção de hidrômetros são a pressão e a vazão, observa-se que pelos resultados obtidos nas simulações a perda de carga do hidrômetro

Tabela 4 - Situações de projeto consideradas nas simulações $\operatorname{Tp}^{(1)}$ : duração do período de pico

\begin{tabular}{|c|c|c|c|c|c|c|c|}
\hline Simulação & Tipologia & População & Tp (1) (hora) & Banheiro suíte & Banheiro Social & Cozinha & Área de serviço \\
\hline A & $1 \mathrm{D} / 1 \mathrm{~B}$ & 2 & $\begin{array}{l}1: 00 \\
1: 30 \\
2: 00\end{array}$ & 1 & --- & 1 & 1 \\
\hline B & $2 \mathrm{D} / 1 \mathrm{~B}$ & 5 & $\begin{array}{l}1: 00 \\
1: 30 \\
2: 00\end{array}$ & --- & 1 & 1 & 1 \\
\hline C & $2 \mathrm{D} / 2 \mathrm{~B}$ & 5 & $\begin{array}{l}1: 00 \\
1: 30 \\
2: 00\end{array}$ & 1 & 1 & 1 & 1 \\
\hline
\end{tabular}

Tabela 5 - Vazão e perda de carga obtidas pelo método da NBR 5.626 (ABNT, 1998) e pelo método probabilístico aberto para o período de pico de uma hora

\begin{tabular}{|c|c|c|c|c|}
\hline \multirow{3}{*}{ Simulação } & \multirow{3}{*}{$\begin{array}{l}\text { Vazão obtida pelo método } \\
\text { probabilístico para período de } \\
\text { pico de } 1 \mathrm{~h}\left({\left.\mathrm{~L} . \mathrm{s}^{-1}\right)}^{-1}\right.\end{array}$} & \multirow{3}{*}{$\begin{array}{l}\text { Vazão obtida pelo método } \\
\text { NBR } 5626 / 1998 \\
(\text { L.s.-1) }\end{array}$} & \multicolumn{2}{|c|}{ Perda de carga (kPa) } \\
\hline & & & \multicolumn{2}{|c|}{ Q máx. do hidrômetro: $1,5 \mathrm{~m}^{3} \cdot \mathrm{h}^{-1}$} \\
\hline & & & $\begin{array}{l}\text { Vazão obtida pelo método } \\
\text { probabilístico }\end{array}$ & $\begin{array}{c}\text { Vazão obtida pelo método } \\
\text { NBR } 5.626 / 1998\end{array}$ \\
\hline A & 0,26 & 0,53 & 38,9 & 161,8 \\
\hline B & 0,33 & 0,53 & 62,7 & 161,8 \\
\hline C & 0,34 & 0,58 & 66,6 & 193,8 \\
\hline
\end{tabular}


calculada conforme a Equação 14 seria muito maior para o valor de vazão obtido pela NBR 5.626 (ABNT,1998). Isso implicaria a escolha de hidrômetros com maiores valores de vazão nominal, que poderiam resultar em submedição. A Tabela 5 ilustra esse fato.

$$
\Delta \mathrm{h}=(36 \times \mathrm{Q})^{2} \times\left(\mathrm{Q}_{\text {máx }}\right)^{-2}
$$

Equação 14

onde:

$\Delta \mathrm{h}$ : perda de carga no hidrômetro, em kPa; Q é a vazão estimada na seção considerada, em L.s ${ }^{-1}$ e $Q_{\text {máx. }}$ : vazão máxima especificada para o hidrômetro, em $\mathrm{m}^{3} \cdot \mathrm{h}^{-1}$.

Com os valores de perda de carga resultantes das vazões obtidas pelo método probabilístico, poder-se-ia especificar hidrômetros com vazão máxima de $1,5 \mathrm{~m}^{3} \cdot \mathrm{h}^{-1}$, na pior das hipóteses, para os pavimentos com maior carga hidrostática, enquanto para os valores de vazão obtidos pelo método da NBR 5.626 (ABNT,1998), não haveria essa possibilidade.

\section{Conclusão}

Observa-se que o método probabilístico oferece grande adaptabilidade às condições de projeto e de uso do sistema, possibilitando que ambos sejam determinados considerando-se:

- o comportamento dos usuários como, por exemplo, tomar um ou mais banhos por dia, de maior ou menor duração, dentro ou fora do período de pico;
- os períodos de pico mais representativos da simultaneidade de utilização dos aparelhos sanitários;

- o tempo de utilização dos aparelhos sanitários e tempo entre usos;

- as vazões dos aparelhos sanitários.

Para a sua devida aplicação, contudo, são necessárias pesquisas em campo para o levantamento das vazões e frequências médias de uso dos aparelhos sanitários. Existem estudos de caso já desenvolvidos nesse sentido no país, sendo necessário ampliar para uma amostra significativa, considerando suas diferentes regiões, com hábitos e características diferenciadas de uso dos aparelhos sanitários. Merece destaque a questão do uso racional de água nos edifícios, a qual deve ser considerada quando do cômputo das vazões e durações de uso dos aparelhos sanitários.

O método probabilístico mostra-se mais adequado para a determinação das vazões de projeto dos sistemas de medição individualizada do que o método da NBR 5.626 (ABNT,1998), pois é possível considerar as reais condições de solicitação do sistema, o que é determinante para a qualidade da medição efetuada. Não basta medir o consumo, é necessário medi-lo com precisão.

Ressalta-se, por fim, que os valores de vazões de projeto em trechos do barrilete apresentam um faixa de variação maior, de 2,7 a 6,5 L. s $^{-1}$ pelo método probabilístico aberto; enquanto o método recomendado pela NBR 5.626 (ABNT,1998) varia de 3,6 a 4,1 L.s. ${ }^{-1}$.

\section{Referências}

ABNT (Associação Brasileira de Normas Técnicas). NBR 5.626: Instalação predial de água fria. Rio de Janeiro, 1998.

CEDIPLAC. ProAcqua. Disponível em: http://www.proacqua.org.br/ default.asp. Acessado em: 4 jan. 2010.

COURTNEY, R.G. A multinomial analysis of water demand. Building and Environment. Pergamon Press, v. 11, p. 203-209, 1976.

GAARSLEV, A. Stochastic Models to estimate the material handling systems in the construction industry. Stanford University. Technical Report, n. 111. Califórnia, EUA, 1969

GONÇALVES, O.M. Formulação de modelo para o estabelecimento de vazões de projeto em sistemas prediais de distribuição de água fria. 1986. Tese (Doutorado em Engenharia Civil) - Escola Politécnica, Universidade de São Paulo, São Paulo, 1986.

GONÇALVES, O.M. Influence of the users behavior in determining the water flow rates in water supply systems in buildings 1989. In: CIB W62. International symposium on water supply and drainage for buildings. Proceedings, 1989.
ILHA, M.S.O. Estudos dos parâmetros relacionados com a utilização de água quente em edifícios residenciais. 204 f. Dissertação (Mestrado em Engenharia Civil) - Escola Politécnica, Universidade de São Paulo, São Paulo, 1991.

MALAN, G.J.; CRABTREE, P.R. The effect of individual meters on the water consumption in apartment buildings. In: CIB W62. International symposium on water supply and drainage for buildings. Proceedings, 1997.

OLIVEIRA, L.H. Fatores que influenciam as vazões de projeto em sistemas de medição individualizada de água. Hydro, São Paulo, v. 11 p. $64-67$, set. 2007

OLIVEIRA, L.H.; ILHA, M.S.O.; GONÇALVES, O.M. A influência do método de determinação de vazões de projeto no dimensionamento de sistemas de medição individualizada. In: X SIMPÓSIO NACIONAL DE SISTEMAS PREDIAIS, 2007, São Carlos. Anais. São Carlos: UFSCar, ANTAC, 2007a, CD ROM.

OLIVEIRA, L.H.; ILHA, M.S.O.; GONÇALVES, O.M. Design flowrate simulation using probabilistic and empiric methods for water submetering system in 
Brazilian multifamily buildings. In: CIB W62. International symposium on water supply and drainage for buildings, ${ }^{33 r d}$ 2007. Brno, Czech Republic. Proceedings. Brno: University of Technology, 2007b, p. 99-109.

PEREIRA, L.G. Avaliação da submedição de água em edificações residenciais unifamiliares: o caso das unidades de interesse social localizadas em Campinas. Dissertação (Mestrado em Engenharia Civil) - Faculdade de Engenharia Civil, Arquitetura e Urbanismo da Universidade Estadual de Campinas, Campinas, 2007.

PERES, A.R.B. Avaliação durante operação de sistemas de medição individualizada de água em edifícios residenciais. Dissertação (Mestrado em Engenharia Civil) - Universidade Federal de Goiás, Goiânia, 2006.

WEBSTER, C.D. An investigation of the use of outlets in multi-storey flats. The Building Services Engineer (JIHVE), v. 39, p. 215-233, Jan., 1972.

YAMADA, E.S. Os impactos de medição individualizada do consumo de água em edifícios residenciais multifamiliares. Dissertação (Mestrado em Engenharia) - Escola Politécnica, Universidade de São Paulo, São Paulo, 2001

ZEEB, W. A holist approach to metering value. In: ANNUAL AMRA SYMPOSIUM, $11^{\text {th }} 1998$ Washington. Proceedings. Washington, 1998. 